\title{
Recommendations for Diagnosis and Treatment of Pseudohypoparathyroidism and Related Disorders: An Updated Practical Tool for Physicians and Patients
}

Giovanna Mantovani $^{\mathrm{a}} \quad$ Murat Bastepe $^{\mathrm{b}}$ David Monk ${ }^{\mathrm{c}}$ Luisa de Sanctis ${ }^{\mathrm{d}}$ Susanne Thiele ${ }^{\mathrm{e}}$ S. Faisal Ahmed ${ }^{f}$ Roberto Bufo ${ }^{g}$ Timothée Choplin ${ }^{h}$ Gianpaolo De Filippo ${ }^{i}$ Guillemette Devernois $^{h}$ Thomas Eggermann ${ }^{j}$ Francesca M. Ellia Aurora Garcia Ramirez ${ }^{k}$ Emily L. Germain-Lee ${ }^{l, m}$ Lionel Groussin ${ }^{n, o}$ Neveen A.T. Hamdy ${ }^{p}$ Patrick Hanna ${ }^{q}$ Olaf Hiort ${ }^{e}$ Harald Jüppner $^{b}$ Peter Kamenický ${ }^{-s}$ Nina Knight ${ }^{t}$ Elvire Le Norcy ${ }^{\mathrm{o}, \mathrm{u}}$ Beatriz Lecumberri ${ }^{\mathrm{v}-\mathrm{x}}$ Michael A. Levine ${ }^{y, z}$ Outi Mäkitie ${ }^{A}$ Regina Martin ${ }^{B}$ Gabriel Ángel Martos-Moreno ${ }^{C-E}$ Manasori Minagawa ${ }^{F}$ Philip Murray ${ }^{G}$ Arrate Pereda ${ }^{H}$ Robert Pignolo' Lars Rejnmark ${ }^{J}$ Rebeca Rodado $^{k}$ Anya Rothenbuhler, ${ }^{r}$ Vrinda Saraff ${ }^{L}$ Ashley H. Shoemaker ${ }^{M}$ Eileen M. Shore ${ }^{N}$ Caroline Silve $^{\mathrm{O}}$ Serap Turan $^{\mathrm{P}}$ Philip Woods $^{\mathrm{t}} \quad$ M. Carola Zillikens ${ }^{\mathrm{Q}}$ Guiomar Perez de Nanclares ${ }^{\mathrm{H}}$ Agnès Linglart ${ }^{\mathrm{q}, \mathrm{r}, \mathrm{K}}$

a'Endocrinology Unit, Department of Clinical Sciences and Community Health, Fondazione IRCCS Ca' Granda Ospedale Maggiore Policlinico, University of Milan, Milan, Italy; ${ }^{b}$ Endocrine Unit, Department of Medicine, Massachusetts General Hospital and Harvard Medical School, Boston, MA, USA; 'Biomedical Research Centre,

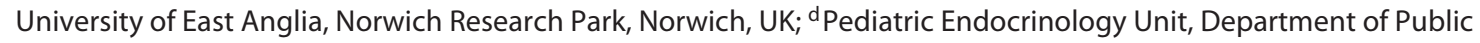
Health and Pediatric Sciences, University of Torino, Torino, Italy; ${ }^{e}$ Division of Pediatric Endocrinology and Diabetes, Department of Pediatrics, University of Lübeck, Lübeck, Germany; 'Developmental Endocrinology Research Group, School of Medicine, Dentistry and Nursing, University of Glasgow, Glasgow, UK; ${ }^{9}$ Italian Progressive Osseous Heteroplasia Association (IPOHA), Foggia, Italy; ${ }^{\text {K } 20, ~ F r e n c h ~ P H P ~ a n d ~ R e l a t e d ~ D i s o r d e r s ~ P a t i e n t ~ A s s o c i a t i o n, ~}$ Jouars-Pontchartrain, France; 'APHP, Department of Medicine for Adolescents, Bicêtre Paris Saclay Hospital (HUPS), Le Kremlin-Bicêtre, France; ' Institute of Human Genetics, Medical Faculty, RWTH Aachen University,

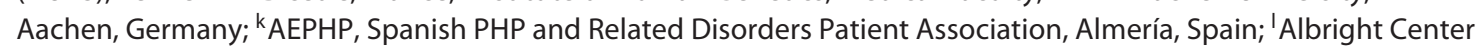
and Center for Rare Bone Disorders, Division of Pediatric Endocrinology and Diabetes, Connecticut Children's

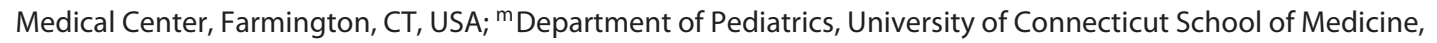
Farmington, CT, USA; ${ }^{n}$ APHP, Department of Endocrinology, Cochin Hospital (HUPC), Paris, France; ${ }^{\circ}$ University of Paris Descartes, Sorbonne Paris Cité, Paris, France; ${ }^{P}$ Division of Endocrinology and Centre for Bone Quality, Department of Medicine, Leiden University Medical Center, Leiden, The Netherlands; ' INSERM U1185, Bicêtre Paris Sud - Paris Saclay University, Le Kremlin-Bicêtre, France; ' $\mathrm{APHP}$, Reference Center for Rare Disorders of Calcium and Phosphate Metabolism, Platform of Expertise Paris-Saclay for Rare Diseases and Filière OSCAR, Bicêtre Paris Saclay Hospital (HUPS), Le Kremlin-Bicêtre, France; ${ }^{\mathrm{A}} \mathrm{APHP}$, Department of Endocrinology and Reproductive Diseases,

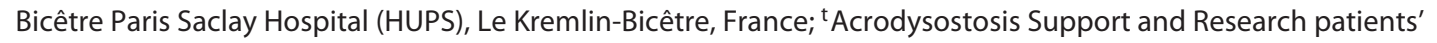
group, London, UK; " APHP, Department of Odontology, Bretonneau Hospital (PNVS), Paris, France; ${ }^{\vee}$ Department of Endocrinology and Nutrition, La Paz University Hospital, Madrid, Spain; ${ }^{\text {w}}$ Department of Medicine, Autonomous University of Madrid (UAM), Madrid, Spain; ${ }^{\times}$Hospital La Paz Institute for Health Research (IdiPAZ), Madrid, Spain; y'Division of Endocrinology and Diabetes and Center for Bone Health, Children's Hospital of Philadelphia,

M.B., D.M., L.S., and S.T. are co-second authors and equally contributed to this work. G.P.N. and A.L. are co-last and corresponding authors.
Guiomar Perez de Nanclares

Molecular (Epi)Genetics Laboratory

BioAraba Reseach Health Institute, Araba University Hospital-Txagorritxu C/Jose Atxotegi s/n, ES-01009 Vitoria-Gasteiz (Spain) gnanclares@osakidetza.eus

\section{Agnès Linglart}

Reference Center for Rare Disorders of Calcium and Phosphate Metabolism Platform of Expertise Paris-Saclay for Rare Diseases, Bicêtre Paris Saclay Hospital 74 Avenue du Général Leclerc, FR-94270 Le Kremlin Bicêtre (France) agnes.linglart@aphp.fr 
Philadelphia, PA, USA; ${ }^{z}$ Department of Pediatrics, University of Pennsylvania Perelman School of Medicine, Philadelphia, PA, USA; ${ }^{A}$ Children's Hospital, University of Helsinki and Helsinki University Hospital, Helsinki, Finland; ${ }^{B}$ Osteometabolic Disorders Unit, Hormone and Molecular Genetics Laboratory (LIM/42), Endocrinology Division, Hospital das Clínicas HCFMUSP, Faculty of Medicine, University of Sao Paulo, Sao Paulo, Brazil; ' Department of Endocrinology, Hospital Infantil Universitario Niño Jesús, Hospital La Princesa Institute for Health Research (IIS La Princesa), Madrid, Spain; D Department of Pediatrics, Autonomous University of Madrid (UAM), Madrid, Spain; ${ }^{E}$ CIBERobn, Instituto de Salud Carlos III, Madrid, Spain; F Division of Endocrinology, Chiba Children's Hospital, Chiba, Japan; ${ }^{G}$ Department of Paediatric Endocrinology, Royal Manchester Children's Hospital, Manchester University NHS Foundation Trust, Manchester, UK; ${ }^{H}$ Molecular (Epi)Genetics Laboratory, BioAraba Research Health Institute, Araba University Hospital-Txagorritxu, Vitoria-Gasteiz, Spain; 'Department of Medicine, Mayo Clinic, Rochester, MN, USA; 'Department of Endocrinology and Internal Medicine, Aarhus University Hospital,

Aarhus, Denmark; ${ }^{\mathrm{K}} \mathrm{APHP}$, Endocrinology and Diabetes for Children, Bicêtre Paris Saclay Hospital (HUPS),

Le Kremlin-Bicêtre, France; 'Department of Endocrinology and Diabetes, Birmingham Children's Hospital,

Birmingham, UK; MPediatric Endocrinology and Diabetes, Vanderbilt University Medical Center, Nashville, TN, USA;

${ }^{N}$ Departments of Orthopedic Surgery and Genetics, Center for Research in FOP and Related Disorders, Perelman

School of Medicine, University of Pennsylvania, Philadelphia, PA, USA; ${ }^{\circ}$ APHP, Service de Biochimie et Génétique Moléculaires, Hôpital Cochin, Paris, France; ${ }^{P}$ Department of Pediatrics, Division of Endocrinology and Diabetes, Marmara University, Istanbul, Turkey; ${ }^{Q}$ Department of Internal Medicine, Bone Center Erasmus MC - University Medical Center Rotterdam, Rotterdam, The Netherlands

\section{Keywords}

Acrodysostosis $\cdot$ Bone disorders $\cdot$ Brachydactyly $\cdot$ Calcium and phosphate metabolism · Consensus · Diagnosis . Management - Ossification . Parathyroid hormone . Pseudohypoparathyroidism · Treatment

\begin{abstract}
Patients affected by pseudohypoparathyroidism (PHP) or related disorders are characterized by physical findings that may include brachydactyly, a short stature, a stocky build, early-onset obesity, ectopic ossifications, and neurodevelopmental deficits, as well as hormonal resistance most prominently to parathyroid hormone (PTH). In addition to these alterations, patients may develop other hormonal resistances, leading to overt or subclinical hypothyroidism, hypogonadism and growth hormone (GH) deficiency, impaired growth without measurable evidence for hormonal abnormalities, type 2 diabetes, and skeletal issues with potentially severe limitation of mobility. PHP and related disorders are primarily clinical diagnoses. Given the variability of the clinical, radiological, and biochemical presentation, establishment of the molecular diagnosis is of critical importance for patients. It facilitates management, including prevention of complications, screening and treatment of endocrine deficits, supportive measures, and appropriate genetic counselling. Based on the first international consensus statement for these disorders, this article provides an updated and readyto-use tool to help physicians and patients outlining relevant interventions and their timing. A life-long coordinated
\end{abstract}

Updated Practical Tool: Diagnosis and Treatment of PHP-Related Disorders and multidisciplinary approach is recommended, starting as far as possible in early infancy and continuing throughout adulthood with an appropriate and timely transition from pediatric to adult care.

(c) 2020 S. Karger AG, Basel

\section{Introduction}

Much progress has been made since 1942 when Albright et al. [1] described pseudohypoparathyroidism (PHP) as a novel disorder of hormone resistance in which hypocalcemia and hyperphosphatemia were due to a decreased responsiveness to parathyroid hormone (PTH). Patients also manifested an unusual appearance characterized by a short stature, brachydactyly, obesity with a round face, and heterotopic ossifications. This was known as Albright hereditary osteodystrophy (AHO). Initially, reports focused on clinical aspects, leading to the identification of a constellation of disorders associated with a similar spectrum of physical characteristics and neurocognitive and endocrine abnormalities which included the different subtypes of PHP (i.e., PHP type 1A due to maternal loss-of-function variants at the GNAS coding sequence [PHP1A], PHP type 1B due to methylation defect at the GNAS locus [PHP1B], pseudo-PHP [PPHP], and progressive osseous heteroplasia $[\mathrm{POH}])$.

Today the term pseudohypoparathyroidism (OMIM 103580 for PHP1A, 603233 for PHP1B, and 612462 for 


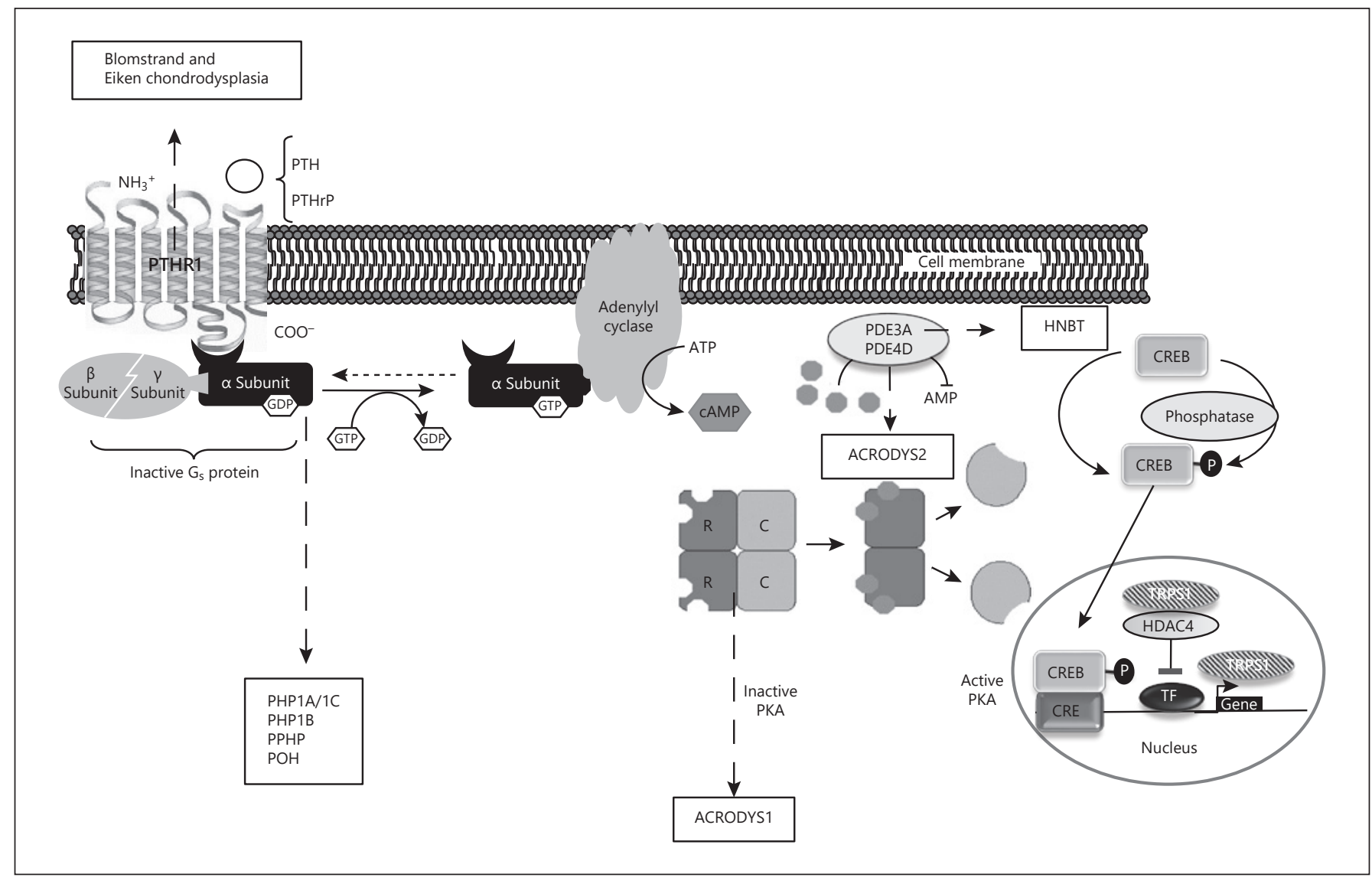

Fig. 1. Molecular defects in the PTH-PTHrP signaling pathway in PHP and related disorders. The main clinical features of PHP and related disorders are due to molecular defects within the PTHPTHrP signaling pathway, with the exception, perhaps, of ectopic ossification. Some of the clinical features result from the impaired signaling of other GPCR such as TSHR. The diseases caused by alterations at the genes codifying the indicated proteins are shown

PHP type 1C [PHP1C]) describes disorders that share biochemical characteristics of hypoparathyroidism, i.e., hypocalcemia and hyperphosphatemia, as a result of proximal tubular resistance to PTH. Some patients present with resistance to other hormones (such as thyroid-stimulating hormone [TSH] and/or gonadotropins, growth-hormone-releasing hormone, and calcitonin).

Patients with PHP1A, and rare PHP1B cases, manifest physical features of AHO due to defects in chondrocyte and osteoblast differentiation, early closure of growth plates, brachydactyly, a short stature, and development of ectopic ossifications. AHO typically develops during late childhood. Years after the description of PHP, Albright and et al. [1] described patients with some physical fea- within square boxes. PTHR1, PTH/PTHrP receptor type 1; G protein, trimers $\alpha, \beta$, and $\gamma$; PKA, tetramers $\mathrm{R}$ (regulatory subunit $1 \mathrm{~A}$; dark grey) and C (catalytic subunit; light grey); HTNB, autosomal dominant hypertension and brachydactyly type E syndrome; TF, transcription factor. Phosphodiesterases: ovals (PDE4D and PDE3A). cAMP: grey diamond.

tures of AHO despite appropriate $\mathrm{PTH}$ responsiveness. Albright et al. [1] originally termed this condition PPHP (OMIM 612463). We know today that POH (OMIM 166350 ) or osteoma cutis belongs to the same disease entity, with a variable extent of the heterotopic ossifications and brachydactyly. On the other side, PTH resistance in absence of the AHO phenotype is the main characteristic of most PHP1B patients [2]. Recent studies have further defined the phenotype of these related disorders including other associated features such as impaired intrauterine growth in PPHP [3], and early-onset obesity [4], frequent respiratory and ENT complications [5], delayed verbal [6] and nonverbal [7] milestones, and cognitive impairment [7], mainly in PHP1A. 
Since the 1990s, PHP1A and PPHP have been known to be caused by heterozygous Gsa-inactivating pathogenic variants $[8,9]$. It was subsequently shown that the disease phenotype associated with the variant depends on the alterations' maternal (PHP1A) or paternal (PPHP) [10]/POH [11] inheritance. The molecular mechanism leading to PHP1B was discovered in 2003. Patients affected with PHP1B present with methylation defects at the GNAS locus [12] (see Molecular Diagnosis). The term PHP type $1 \mathrm{C}$ was initially used for patients displaying a PHP1A phenotype yet a biochemical normal Gsa activity; the denomination should now be abandoned and patients should be referred to as PHP1A, as they carry maternally inherited inactivating pathogenic Gsa variants.

New biochemical and molecular techniques have uncovered that disorders similar to PHP, such as acrodysostosis (OMIM 101800) [13, 14], are due to different defects within various genes involved in the stimulatory G-proteincoupled receptor signaling pathway [15] (e.g., GNAS [2, 16, 17], PRKAR1A [14], PDE4D [13, 18], or PDE3A [19]). Today, molecular analyses can identify de novo or inherited genetic or epigenetic alterations in around $80-90 \%$ of patients with PHP or related disorders [20,21] (Fig. 1).

Since publication of the original consensus statement for PHP and related disorders [22], new relevant findings have been published. Therefore, with the aim of disseminating and updating the international consensus statement, the 3 main investigators (A.L., G.M., and G.P.N.) together with 34 of the 37 experts collaborated on this shortened and updated paper.

The literature search was updated from December 18, 2016, to December 31,2019, using the same key terms as in the previous version, leading to a total of over 1,000 articles.

The addition of the recently published evidence did not modify the content of the previously published recommendations but further strengthened the underlying background and experts' opinions and prompted us to develop a more concise and practical tool designed to help health care professionals involved in the management of patients with PHP and patients and their families.

\section{Clinical Diagnosis and Management}

PHP and the aforementioned disorders share a common defect in the cAMP signaling pathway downstream of the PTH/PTHrP receptor. Despite this unifying molecular umbrella, presentation and disease severity can vary considerably between affected individuals, even among patients carrying the same genetic alteration,

Updated Practical Tool: Diagnosis and

Treatment of PHP-Related Disorders highlighting the important clinical and molecular overlap of these diseases. Newborns and young infants usually present with unspecific features such as being born small for gestational age (SGA) [23], early-onset obesity [3], or transient hypothyroidism. In the absence of familial history or typical symptoms such as ectopic ossifications, diagnosis may be delayed for years due to a lack of recognition of the syndrome and associated features. Later in life, growth failure, brachydactyly, obesity, and/or hypocalcemia leading to neuromuscular symptoms or even seizures often leads to investigations and identification of the underlying cause.

Therefore, diagnosis of PHP and related disorders should be based on clinical and biochemical characteristics and, in some cases, the family history.

The following major features should be present in order to diagnose a patient with PHP or a related disorder: PTH resistance and/or ectopic ossifications, and/or earlyonset (before 2 years of age) obesity associated with TSH resistance, and/or AHO. In addition, other features can be considered as supporting the diagnosis of PHP and related disorders: unexplained primary hypothyroidism, hypercalcitoninemia, hypogonadism, growth hormone (GH) deficiency, cognitive impairment, hearing impairment, craniosynostosis and neurosurgical features, tooth ankylosis, oligodontia, cataract and/or CNS calcifications, sleep apnea, ear infections, asthma, and restricted fetal growth (Fig. 2).

Once a clinical suspicion exists, molecular analyses are critically important for genetic counselling and in some cases for diagnosis, particularly when there is significant overlap in clinical features (e.g., PHP1A vs. acrodysostosis). Nowadays, the genetic or epigenetic diagnosis relies on the most likely identified causes of the disease at the time of analysis according to the algorithm (Fig. 3). The use of genetic and epigenetic analyses to diagnose patients with PHP and related disorders has reduced the need for administration of exogenous PTH or assessment of Gsa bioactivity.

Altogether, a correct diagnosis will guide appropriate management including prevention of complications, lifestyle adjustments, screening and treatment of endocrine deficits, and appropriate genetic counselling.

Sufficient prospective clinical trials and outcomes data in PHP and related disorders is lacking. Thus, management guidelines are mainly based on experts' consensus. We have summarized in this document (see below) and in Table 1 the principal multidisciplinary interventions that should take place during the follow-up of these patients. 


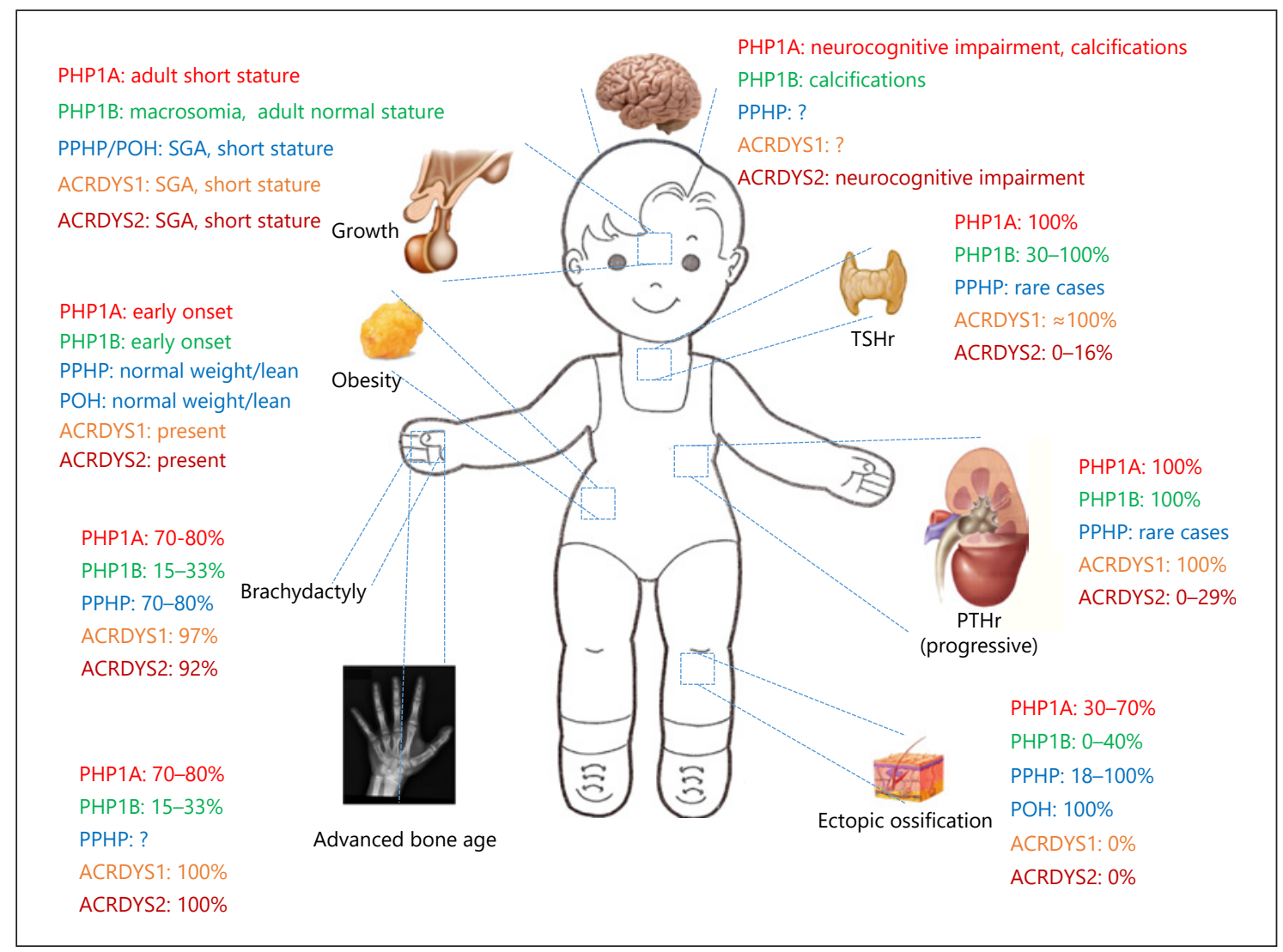

Fig. 2. Main clinical features of PHP and related disorders. PHP and related disorders affect many organs unequally. The clinical and biochemical features of the main diseases have been represented with their frequency when known. ACRDYS1, acrodysostosis due to a pathogenic variant in PRKAR1A; ACRDYS2, acrodysostosis due to alterations in PDE4D.

\section{Resistance to PTH}

PTH resistance is the hallmark of PHP, found in 45$80 \%$ [24] of patients, particularly in those with PHP1A and $1 \mathrm{~B}$. It is defined by the association of hypocalcemia, hyperphosphatemia and elevated serum levels of PTH in the absence of vitamin $\mathrm{D}$ deficiency, abnormal magnesium levels, and/or renal insufficiency [22]. PTH resistance is usually absent at birth and develops over time [25]; in addition, diagnosis maybe difficult in the absence of one or several biochemical features, e.g., hypocalcemia or hyperphosphatemia [13, 18, 22, 26-28]. Typically, in children, symptoms appear during periods of rapid growth, most likely because of increased calcium and vitamin D requirements [29]. The screening and follow-up of PTH resistance should include measurement of PTH, 25-OH vitamin $\mathrm{D}$, calcium, and phosphate every 3-6 months in children and at least yearly in adults. Monitor- ing should be more frequent in symptomatic individuals and during acute phases of growth, intercurrent illness, pregnancy, and breastfeeding, when dosage requirements for active vitamin $\mathrm{D}$ metabolites or analogs might change. Patients and/or their families should be taught to recognize clinical signs of hypocalcemia and hypercalcemia [22].

The management of severe symptomatic hypocalcemia does not differ from that of hypoparathyroidism [30]. However, treatment using activated forms of vitamin D combined with (in most cases) oral calcium supplementation should target levels of calcium and phosphorus within the normal range while avoiding hypercalciuria; PTH levels should be within mid-normal to up to 2 times the upper limit of normal as higher levels of PTH might have adverse effects on skeletal mineralization or on the growth plate and evolve towards tertiary hyperparathyroidism [31-34]. Regardless of the level of serum 


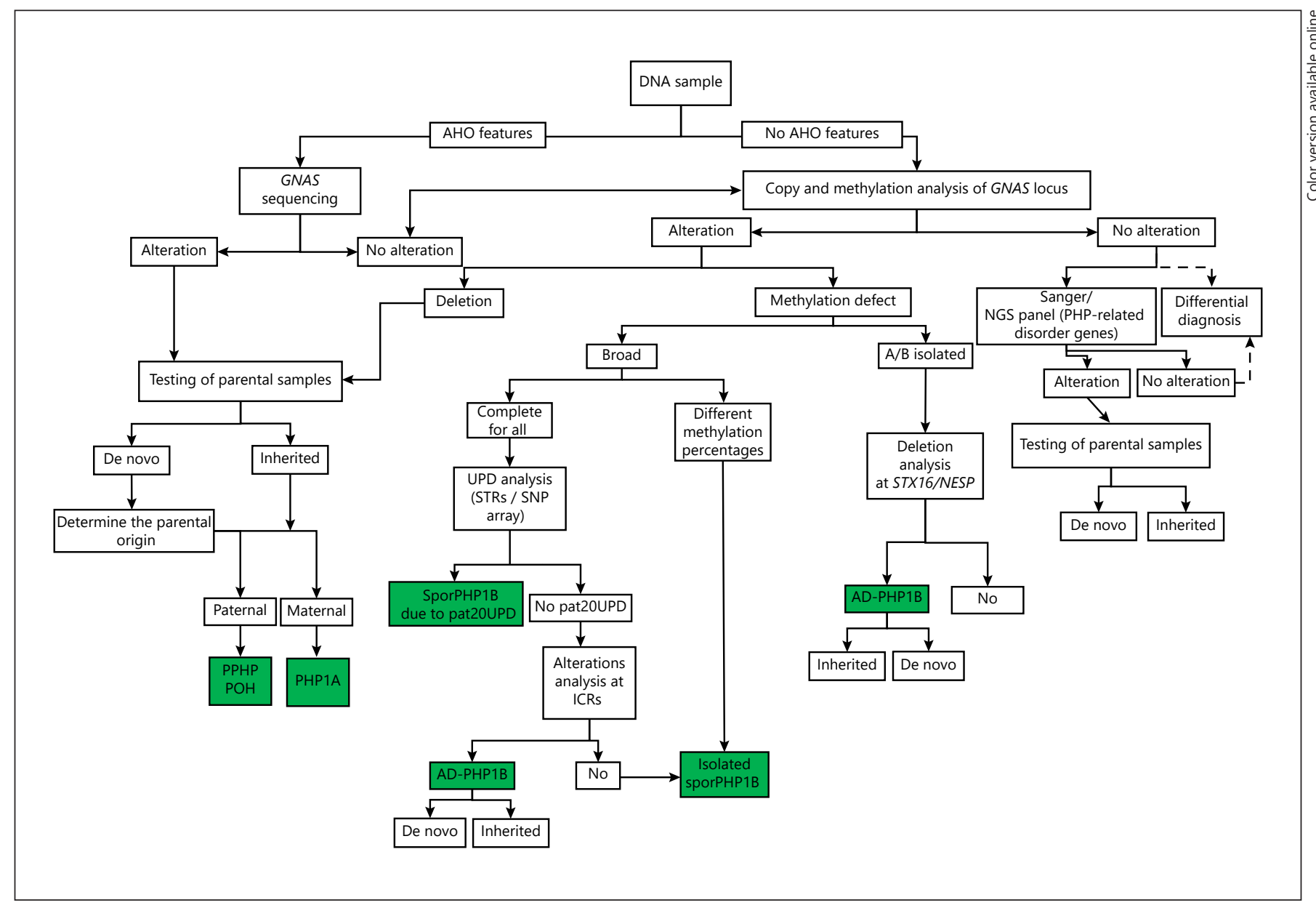

Fig. 3. Molecular algorithm for confirmation of the diagnosis of $\mathrm{PHP}$ and related disorders. If patients present with AHO, genetic alterations at GNAS should be studied, including point variants (sequencing) and genomic rearrangements (such as MLPA and aCGH). In the absence of AHO, epigenetic alterations should be analyzed first. According to the results obtained for the methylation status, further tests are needed to reach the final diagnosis; if the methylation defect is restricted to GNAS A/B:TSS DMR, STX16 deletions should be screened for, and, if present, the diagnosis of AD-PHP1B is confirmed; if the methylation is modified at the 4 DMR, paternal uniparental disomy of chromosome 20 (UPD[20q] pat) should be screened for; in the absence of UPD(20q)pat, dele-

calcium, treatment with active vitamin D analogs should be considered when PTH levels reach more than twice the upper limit of normal. Calcium supplements should also be considered, depending on the calcium dietary intake. Normal levels of $25-\mathrm{OH}$ vitamin $\mathrm{D}$ should be maintained for all patients with appropriate supplementation [22].

Patients with PHP and related disorders rarely develop hypercalciuria and/or nephrocalcinosis because of tions at NESP should be screened for; if no genetic cause is identified as the cause of the methylation defect, the sporadic form of the disease (spor-PHP1B) is suspected. After exclusion of the GNAS locus as the cause of the phenotype, and in patients with AHO, PHP-related genes (i.e., at least PDE4D and PRKAR1A) should be sequenced. RT-PCR, reverse transcription polymerase chain reaction; SNP, single-nucleotide polymorphism; NGS, next-generation sequencing; A/B: GNAS A/B:TSS-DMR; STR, short tandem repeats (microsatellites); UPD, uniparental disomy; WES, whole exome sequencing; WGS, whole genome sequencing; ICR, imprinting control region; VUS, variant of unknown significance. the preserved PTH sensitivity of the distal renal convoluted tubules [29, 35, 36]. However, episodes of nephrolithiasis have been seldom observed (unpubl. obs.) in patients with PHP1A and PHP1B, particularly after completion of pubertal growth. Monitoring of urine calcium levels is recommended at regular intervals during treatment, as well as appropriate renal imaging in patients with persistent hypercalciuria on repeated measurements $[22,30]$. 
Table 1. Summary of the main interventions during the follow-up of patients with PHP and related disorders

\begin{tabular}{|c|c|c|c|c|}
\hline Action point & $\begin{array}{l}\text { Infancy } \\
\text { (newborn to } \\
2 \text { years) }\end{array}$ & $\begin{array}{l}\text { Early childhood } \\
\text { (2-6 years) }\end{array}$ & $\begin{array}{l}\text { Late childhood } \\
\text { to adolescence }\end{array}$ & Adulthood \\
\hline \multicolumn{5}{|l|}{ Anticipatory guidance } \\
\hline Family support & $\checkmark$ & $\checkmark$ & $\checkmark$ & $\mathrm{N} / \mathrm{A}$ \\
\hline Genetic counselling & At diagnosis & At diagnosis & At diagnosis & At diagnosis \\
\hline Psychosocial evaluation $^{\mathrm{a}}$ & N/A & $\checkmark$ & $S$ & $\mathrm{~S}$ \\
\hline \multicolumn{5}{|l|}{ Medical evaluation } \\
\hline \multicolumn{5}{|l|}{ Physical examination } \\
\hline Linear growth & $\checkmark$ & $\checkmark$ & $\checkmark$ & $\mathrm{N} / \mathrm{A}$ \\
\hline Weight gain/BMI & $\checkmark$ & $\checkmark$ & $\checkmark$ & $\checkmark$ \\
\hline Ectopic ossifications & $\checkmark$ & $\checkmark$ & $\checkmark$ & $\mathrm{S}$ \\
\hline Development and/or cognition & $\checkmark$ & $\checkmark$ & $\mathrm{S}$ & $\mathrm{S}$ \\
\hline Descended testis & $\checkmark$ & $\checkmark$ & If not checked before & If not checked before \\
\hline Pubertal development & $\mathrm{N} / \mathrm{A}$ & $\mathrm{N} / \mathrm{A}$ & $\checkmark($ biochemistry if delayed) & $\mathrm{N} / \mathrm{A}$ \\
\hline Fertility and sexual function & $\mathrm{N} / \mathrm{A}$ & $\mathrm{N} / \mathrm{A}$ & & $\checkmark$ \\
\hline Blood pressure & $\mathrm{N} / \mathrm{A}$ & $\sqrt{ }^{\mathrm{b}}$ & $\checkmark$ & $\checkmark$ \\
\hline \multicolumn{5}{|l|}{ Biochemical analyses } \\
\hline \multicolumn{5}{|l|}{ Calcium-phosphorus } \\
\hline metabolism & $\checkmark$ & $\checkmark$ & $\checkmark$ & $\checkmark$ \\
\hline Renal function & $\checkmark$ & $\checkmark$ & $\checkmark$ & $\checkmark$ \\
\hline Thyroid & $\checkmark$ & $\checkmark$ & $\checkmark$ & $\checkmark$ \\
\hline GH secretion & $\mathrm{N} / \mathrm{A}$ & $\checkmark$ & $\checkmark$ & S \\
\hline Glucose and lipid metabolism & $\mathrm{N} / \mathrm{A}$ & $\checkmark$ & $\checkmark$ & $\checkmark$ \\
\hline Fertility & $\mathrm{N} / \mathrm{A}$ & $\mathrm{N} / \mathrm{A}$ & $\mathrm{S}$ & $\mathrm{S}$ \\
\hline \multicolumn{5}{|l|}{ Radiological studies } \\
\hline Bone age radiography & N/A & $\begin{array}{l}\checkmark \text { (in case of growth } \\
\text { deceleration) }\end{array}$ & $\begin{array}{l}\checkmark \text { (in case of growth } \\
\text { deceleration) }\end{array}$ & N/A \\
\hline Orthodontic and/or dental & $\mathrm{N} / \mathrm{A}$ & $\checkmark$ & $\checkmark$ & S \\
\hline Age-appropriate renal imaging & $\sqrt{ }^{c}$ & $\sqrt{ }^{\mathrm{c}}$ & $\checkmark$ & $\sqrt{ }^{c}$ \\
\hline
\end{tabular}

Adapted from Mantovani et al. [23]. $\checkmark$, to be performed at diagnosis of PHP and related disorders and annually thereafter; S, subjective (by history and physical examination); N/A, not applicable. ${ }^{a}$ Refers to social interactions and relations to peers. ${ }^{b}$ At least 1 time year, with an appropriate sized cuff. ${ }^{c}$ Annually in case of persistent hypercalciuria or nephrocalcinosis.

Chronic hypocalcemia with hyperphosphatemia can result in an elevated calcium $\times$ phosphate product, which can lead to ectopic calcification (not to be confused with the ectopic ossification of AHO that occurs independently of serum levels of calcium and phosphate). Intracranial calcifications of the basal ganglia resemble those occurring in Fahr syndrome due to pathogenic variants in the SLC20A2 gene; note that patients with PHP may often have additional calcification of the cerebral white matter [37]. So far, brain calcifications have not been described in patients with PPHP or $\mathrm{POH}$ or those with an alteration in the PRKAR1A or PDE4D genes [13, 14, 38-41]. Ectopic depositions of calcium and phosphorus may occur in the eyes, leading to posterior subcapsular cataract or corneal opacities [41-45]. A brain CT scan is indicated only in the case of neurological manifestations, while systematic and regular ophthalmologic examination is recommended to diagnose or manage cataracts.

Finally, PHP is often associated with dental and oral features such as failure of tooth eruption, impaction of primary molars, hypodontia, enamel hypoplasia, malocclusion, gingival hyperplasia, and gingivitis with spontaneous bleeding and pain [46-49]. Regular dental reviews every 6-12 months are recommended, at least during childhood $[22,50]$.

\section{Ectopic Ossification}

Ectopic ossifications are found in 100 and $80-100 \%$ of patients with $\mathrm{POH}$ and $\mathrm{PPHP} / \mathrm{AHO}$, respectively, in 30$70 \%$ of PHP1A patients, and very sporadically in those 
with PHP1B, while they have never been reported in patients with acrodysostosis [27, 51]. Ectopic ossifications should therefore be considered as a specific consequence of GNAS molecular alterations, especially when located on the paternal allele [52]; Gsa deficiency in mesenchymal stem cells favors de novo formation of extraskeletal islands of ectopic bone in dermis and subcutaneous fat $[53,54]$.

In contrast to what has been described in Gnas knockout mouse models of AHO [55], and unlike fibrodysplasia ossificans progressiva (FOP), there is no scientific evidence that inflammation or traumatic events contribute to ectopic bone formation in GNAS-related conditions $[56,57]$. This notwithstanding, ectopic bone formation often develops, in GNAS related disorders, in locations subjected to high pressure loads, such as the heel [58].

$\mathrm{POH}$ is defined by ossifications located in and extending towards connective tissues, muscles, tendons, and ligaments $[11,52,57]$. In contrast, ectopic bone formation remains superficial in osteoma cutis, PHP1A, PPHP, or AHO.

Ectopic ossifications are uncommon in the general population, and the presence of these lesions should trigger a clinical and biochemical work up to search for signs of AHO, PTH and TSH resistance, or FOP. Skin biopsy is not necessary in obvious cases and it is contraindicated in case of suspicion of FOP.

Due to the rarity of these conditions, limited information is available about prognosis, and so far no effective treatments exist for the management or prevention of ectopic ossifications.

Cutaneous bony plaques should be investigated by careful clinical examination at each visit, especially in patients with pathogenic or probably pathogenic variants on the GNAS paternal allele (POH and PPHP). Patients and families should be instructed about self-examination. The location and size of the ossifications, involvement of joints and impairment of movement and bone growth, and evolution during puberty or rapid growth should be documented at each visit.

Imaging of ossifications should be performed using CT or MRI only in the case of painful or symptomatic lesions, if joint or organ function is being jeopardized, or when considering surgical excision.

Physical therapy and meticulous skin care are critical for the prevention of complications due to ectopic ossifications. Due to a high risk of recurrence, surgical excision should be limited to well-delimitated, superficial lesions causing pain and/or movement impairment [11, 22, 57]. In ossifications involving joints, immobilization, e.g.,

Updated Practical Tool: Diagnosis and

Treatment of PHP-Related Disorders through casts, should be avoided to prevent ankyloses. No evidence supports the use of nonsteroidal anti-inflammatory drugs, bisphosphonates, or steroids in primary or perisurgical treatment of asymptomatic ectopic ossifications [22].

\section{Brachydactyly}

Brachydactyly is not specific to PHP and related disorders. Affected patients display brachydactyly type E [59], with a high degree of variability in frequency and severity. Brachydactyly is found in the majority of patients with PHP1A and PPHP (70-80\%), in few with PHP1B (15$33 \%$ ), and in all patients with acrodysostosis [22] (Fig. 2).

Brachydactyly develops over time and might not be present or visible in early life, except in patients with acrodysostosis $[14,60]$. Clinical and radiological examination of the hands and feet is important from early childhood onwards to establish the diagnosis. It may impair fine motor skills, such as handwriting [61]. In some patients occupational therapy and/or appropriate orthopedic devices, e.g., special shoes and orthopedic insoles, may be indicated [22].

Additional bone features, such as carpal tunnel syndrome [61], Madelung deformity [62], spinal stenosis [63], acro-osteolysis, phalangeal cone-shaped epiphyses, and craniosynostosis [64] have been described. Depending on the functional consequences, these skeletal manifestations may require a specific multidisciplinary evaluation and orthopedic corrective surgery [22].

\section{Management of Growth and GH Deficiency}

The majority of PHP1A and PPHP patients display adult short stature, $2.5 \mathrm{SD}$ below the mean in average, despite having a normal length/height during childhood [3]. The short stature is even more pronounced in acrodysostosis, with the final height being on average -3.5 SD ( -8.8 to -0.5 SD) [22]. Noticeably, most patients with a paternal GNAS pathogenic variant (i.e., patients with PPHP or POH) and patients with acrodysostosis show restricted fetal growth and are thus born SGA [22]. Intrauterine growth restriction, advanced bone maturation, an impaired pubertal growth spurt, and, in PHP1A, GH-releasing hormone resistance and consequently $\mathrm{GH}$ deficiency can contribute to the premature cessation of growth and a short stature in adulthood [3, 22 ]. Careful and regular monitoring of growth, skeletal 
maturation and GH secretion is therefore advised in all affected children, starting around the age of 3-6 years. Patients born SGA who do not demonstrate appropriate catch-up growth or patients showing a GH deficiency should be rapidly considered for treatment with $\mathrm{rhGH}$ [22]. As of today, there is insufficient evidence to establish the efficacy and safety of pubertal blockers to increase the final height in these patients [65]. In contrast to PHP1A and PPHP patients, and despite an enhanced growth velocity during infancy, $\mathrm{PHP} 1 \mathrm{~B}$ patients display adult heights similar to those of the general population $[3,66]$.

\section{Obesity}

Patients with PHP1A or PHP1B develop early-onset obesity, usually within the first 2 years of life; this may be the first and only symptom in many patients until the diagnosis is established during adolescence or adulthood $[3,4,67,68]$. Several mechanisms may contribute to excessive acquisition and maintenance of fat mass, including a defect in the Gsa-dependent melanocortin signaling pathway (possibly responsible for the patients' hyperphagic trait $[68,69])$, decreased resting energy expenditure compared to obese controls $[68,70,71]$, low sympathetic nervous system activity, decreased lipolysis [72], and GHreleasing hormone resistance in the pituitary [73, 74]. Overall, we now know that obesity or overweight is associated with all types of PHP and related disorders [22], with the exception of $\mathrm{POH}, \mathrm{PPHP}$, and osteoma cutis [3, $52,57,75,76]$. Once the diagnosis is made, BMI and eating behaviors should be regularly monitored. Patients, parents, and families should be provided with psychological support and educational programs, as early as possible, even in the presence of a normal BMI as a preventive strategy, also taking into account the low resting energy expenditure of these patients [3].

Sleep apnea, a well-known complication of obesity, has been reported to be more frequent in patients affected with PHP1A $[77,78]$ and may also be present in acrodysostosis [40]. Phenotypically, these patients present with round faces, a flattened nasal bridge, and/or maxillary hypoplasia $[26,50]$ which, combined with obesity, mechanically contributes to the development of sleep and respiratory disturbances [70,77]. All patients with PHP and related disorders should therefore be screened for restless sleep, snoring, inattentiveness, and daytime somnolence and, if present, polysomnography is recommended.

\section{Metabolic Syndrome}

Decreased insulin sensitivity and type 2 diabetes are present in a large proportion of adult PHP1A patients and may not be solely related to obesity [79]. Postprandial hyperglycemia is common in children with PHP1A and PHP1B [71]. The lipid profile is not profoundly affected in PHP1A patients $[69,80]$. Hypertension was reported in 1 study of PHP [81], yet the incidence of cardiovascular diseases was not increased in cohort studies conducted in Denmark $[41,80]$. Other studies have failed to find an increased risk of hypertension compared to matched controls $[69,71,79]$. Overall, we propose inclusion of regular monitoring of blood pressure, lipid profile, and glucose metabolism parameters within the regular multidisciplinary follow-up of patients affected with PHP and related disorders.

\section{Cognitive Features}

Cognitive impairment has been reported in $40-70 \%$ of patients with PHP1A and in $0-10 \%$ of patients with $\mathrm{PPHP}$ or $\mathrm{POH}$, and it is rarely observed in patients with PHP1B and has a variable prevalence in patients with acrodysostosis [22]. Cognitive performance studies have been undertaken only in PHP1A and they have shown reduced scores in comparison to peers $[6,37,82,83]$, with an average IQ of 85.9 and a reduction of 21.5 IQ points below an unaffected sibling [7]. Patients with PHP1A have been found to have impaired executive function, delayed adaptive behavior skills, and increased rates of attention deficit hyperactivity disorder [7]. One retrospective review of developmental milestones showed a greater delay in language compared with gross motor skills, with and a tendency to improve during late childhood [6]. Neurological and neuropsychiatric manifestations can be linked to the function in addition to the role of Gsa in brain development [84], and other organic CNS alterations, including Chiari 1 malformation [85-87] or prolonged periods of hypocalcemia [83, 87] found in some patients. Patients with PHP and related disorders should be referred to a neuropsychologist for neurocognitive and/or behavioral assessment at diagnosis or at preschool age, especially patients with PHP1A and acrodysostosis due to $P D E 4 D$ pathogenic variants mutations. Most patients will require specialized educational assistance [7]. 


\section{TSH Resistance}

TSH resistance is not as severe as PTH resistance due to partial Gsa imprinting in the thyroid tissue [88-90]. Most patients with PHP1A $[51,74]$ present elevated serum levels of TSH, a small thyroid gland, and normal or only mildly depressed serum levels of thyroid hormone. Elevated levels of TSH due to TSH resistance are often present at birth; some patients may be diagnosed through neonatal screening [22]. In contrast, $\mathrm{PHP} 1 \mathrm{~B}$ patients display TSH levels at the upper end of normal or mildly elevated levels [22]. TSH resistance is present in patients with acrodysostosis due to pathogenic variants at PRKAR1A but not in those at $P D E 4 D[26,27]$. Despite a prompt diagnosis of hypothyroidism after birth and initiation of treatment, this does not seem to prevent motor or cognitive delay [82].

In children and adults, investigation, monitoring, and treatment objectives do not differ from other etiologies of hypothyroidism/subclinical hypothyroidism, including hypothyroidism related to TSH resistance [22, 91].

\section{Alterations in Gonadal Function}

\section{Gonadal Function and Puberty}

Resistance to gonadotrophins is more subtle than resistance to other hormones such as PTH and TSH. This suggests that PHP1A patients display only a partial resistance to gonadotropins [22, 92]. Clinically, patients may present with menstrual irregularities in girls [92], cryptorchidism in boys [93 and experts' experience], and a blunted or absent pubertal growth spurt in adolescents [3] with PHP1A. PHP1B and PPHP patients seem to have a normal gonadal function [94], while a variable resistance to gonadotropins has been described in patients with acrodysostosis and pathogenic variants in the PRKAR1A gene [26].

In children with PHP or related disorders, Tanner staging of sexual maturation and testicular descent and location should be regularly assessed. As skeletal maturation is typically advanced in these children, bone age should be radiographically determined. Conversely, biochemical assessment of gonadal status is not recommended unless clinically indicated. Cryptorchidism and/or hypogonadism, when present, should be corrected and managed according to standard recommendations [22].

\section{Fertility and Pregnancy}

Assisted and spontaneous pregnancies have been reported in women with PHP and related disorders [22,
92, 95]. Men with PHP1A have also fathered children. For disease transmission risks, see Molecular Diagnosis.

In the case of hypocalcemia and/or hypothyroidism, pregnant women with PHP and related disorders should be monitored following the international guidelines for any pregnancy associated with these disturbances. Vaginal delivery may be contraindicated due to the reduced pelvic size and the decreased range of motion of the hips due to local ossifications [22]. The newborn should be evaluated for the presence of skin ossifications and levels of TSH, calcium, and phosphorus. Breastfeeding is not contraindicated, but close follow-up and clinical monitoring of the baby are advised [22].

\section{Menopause and Osteoporosis}

Although patients with PHP do have several potential risk factors for bone fragility, they do not generally demonstrate evidence for a decreased bone density and/or an increased fracture risk [41, 96, 97]; in this context, routine DXA measurement is not indicated [22]. On the other hand, further investigation is required should a diagnosis of osteoporosis be suspected, for instance after sustaining a low trauma fracture or in the case of skeleton unloading (e.g., joint ankyloses secondary to aberrant ossification). Patients should then be screened for potential secondary causes of bone loss such as vitamin D deficiency, hypogonadism, or GH deficiency, and all efforts should be made to correct these before treating the osteoporosis if still required according to national and international standard recommendations.

\section{Other Hormone Resistances}

Elevated calcitonin levels, most likely due to calcitonin resistance, have been reported in PHP1A [98, 99], PHP1B, and acrodysostosis patients with PRKAR1A pathogenic variants [14]. They may be used to support the diagnosis of PHP and related disorders. Additional resistance to hormones that mediate their actions through Gsa-coupled receptors has also been previously reported, although the clinical relevance of these abnormalities remains to be established [100]. Screening of additional hormone resistances, and calcitonin measurement, is not recommended in patients with PHP and related disorders, except for diagnostic purposes [22]. 


\section{Molecular Diagnosis}

The main subtypes of PHP and related disorders are caused by de novo or autosomal dominant inherited inactivating genetic pathogenic variants within the genes of the PTH/PTHrP signaling pathway [15] or by epigenetic alterations at the GNAS locus. The GNAS locus presents 4 distinct differentially methylated regions (DMR; online suppl.Fig. 1, seewww.karger.com/doi/10.1159/000508985 for all online suppl. material): the paternally methylated region (GNAS-NESP:TSS-DMR) and 3 maternally methylated regions (GNAS-AS1:TSS-DMR, GNAS-XL:Ex1DMR and GNAS A/B:TSS-DMR).

PHP1A is caused by inactivating pathogenic variants on the maternal allele of the GNAS gene, including both single-nucleotide and copy number variants $[8,9,22]$. When the pathogenic variants are on the paternal allele, the outcome is mainly PPHP but it can also include osteoma cutis or POH $[11,22]$. Single-nucleotide variants can be easily detected by sequence analysis, whereas genomic rearrangements can be detected by quantitative methods [101]. Determination of the affected allele in de novo cases is becoming relevant, as a few PPHP patients may also develop hormone resistance [102]. Genetic counseling is critical for PHP and related disorders; patients with GNAS genetic variants have a $50 \%$ chance of transmitting the molecular defect. Depending on parental sex, their offspring will develop PPHP, osteoma cutis, or $\mathrm{POH}$ (when the transmitting patient is male) or PHP1A (when the transmitting patient is female).

Loss of methylation at GNAS A/B:TSS-DMR is detected in all patients with PHP1B $[22,103]$. When it is the only affected DMR (15-20\% of PHP1B cases) [21], it is most often the consequence of an alteration in the maternal allele of cis-acting control elements within STX16 [12]. Other maternally inherited deletions and duplications have also been identified in some rare familial cases, affecting either an isolated GNAS A/B:TSS-DMR or all 4 DMR [22]. This clinical form is classified as AD-PHP1B, due to its autosomal dominant mode of inheritance when maternally inherited (i.e., paternally inherited deletions are not associated with methylation defects) [12].

On the other hand, sporadic PHP1B is often associated with methylation defects at 2 or more DMR, in addition to GNAS A/B:TSS-DMR, with no identified underlying genetic mechanism [104]. In around 8-10\% [21, 105] of these sporadic cases, the methylation anomalies are caused by paternal uniparental disomy of the chromosomal region comprising GNAS (UPD[20q]pat) [22, 106]. In these patients, the recurrence and transmission risks are expected to be similar to those of the general population.

Although GNAS methylation defects can be detected through the use of several methods, a methylation sensitive-MLPA (MS-MLPA) kit from MRC-Holland (MSMLPA ME031 GNAS) enables the detection simultaneously of methylation defects at the different GNAS DMR as well as STX16 and NESP/AS deletions and deletions encompassing GNAS [107].

Paternal uniparental isodisomy can be analyzed either by microsatellite (short tandem repeats) typing or SNP array.

In brief, in individuals with a suspected diagnosis of PHP, molecular diagnosis must include DNA sequence, methylation, and CNV analyses at the GNAS locus following the proposed algorithm described in Figure 3.

Acrodysostosis can be caused by heterozygous point pathogenic variants in PRKAR1A or PDE4D [13, 14, 18], so they can be easily detected by sequencing. They mostly occur de novo [22], so the recurrence risk is similar to that of the general population. As it presents an autosomal dominant way of inheritance, patients have a $50 \%$ of chance of passing on the molecular defect and the disease to their children.

\section{Conclusions}

Patients with PHP and related disorders may display a highly heterogeneous and progressive clinical picture over their life span from infancy to adulthood, which renders a life-long multidisciplinary approach mandatory. Each of the many clinical aspects and potential complications of the disease should be managed by health care professionals with expertise in these disorders, preferably when possible at referral centers. In addition, the different and complex genetic and epigenetic defects underlying these disorders also require a specialized approach in order to establish a correct molecular diagnosis, which is often difficult and time consuming for both patients and their families, but that might in turn help clinicians to look for specific clinical manifestations with consequent appropriate management.

Following up on the recent publication of the first international consensus statement on these disorders, this article provides an updated, concise, and ready-to-use tool for physicians and patients, with Table 1 summarizing the main interventions as well as their timing.

Given the lack of strong evidence-based data, particularly for the management of these patients, there is an 
urgent need to implement registries with large cohorts of patients, to better understand the natural history of PHP and related disorders, to identify the intersections as well as the specificities of these clinically heterogeneous but closely related diseases, and, last but not least, to enable the development of novel disease-specific therapies.

\section{Acknowledgement}

The COST action BM1208 (European Network for Human Congenital Imprinting Disorders, http://www.imprinting-disorders.eu), the European Reference Network on Rare Endocrine Conditions (ENDO-ERN), the European Reference Network on Rare Bone Disorders (BOND-ERN), the European Calcified Tissue Society (ECTS), the Asian Pacific Pediatric Endocrine Society (APPES), the European Society of Human Genetics (ESHG), the Pediatric Endocrine Society (PES), the European Society of Endocrinology (ESE), and the European Society for Paediatric Endocrinology (ESPE) endorsed the first consensus statement on PHP and related disorders.

We are very grateful to the Spanish PHP patient association (Asociación Española de PHP; AEPHP), the French PHP Patient Association (K20), the Italian Association of POH (IPOHA), the Acrodysostosis Support Group, and the patients and their families for their contributions to this study.

\section{Conflict of Interest Statement}

The authors declare no competing interests.

\section{Funding Sources}

The European Network on Pseudohypoparathyroidism (EuroPHPnet), which promoted the consensus, was funded by an ESPE grant to A.L. The consensus statement and the series of consensus meetings were supported by funds from the COST action BM1208 on imprinting disorders (www.imprinting-disorders.eu), the ESPE, and the ESE. Travel costs and housing of the representatives of the APPES and of the PES were supported by their societies. We received no funding from pharmaceutical companies.

\section{Author Contributions}

G.P.N., G.M., and A.L. researched data for this article, contributed to discussion of the content, wrote this article, and reviewed and/or edited this paper before submission. M.B., D.M., L.S., S.T., S.F.A., R.B., T.C., G.D.F., G.D., T.E., F.M.E., A.G.R., E.L.G.-L., L.G., N.A.T.H., P.H., O.H., H.J., P.K., N.K., E.L.N., B.L., M.A.L., O.M., R.M, G.A.M.-M., M.M., P.M., A.P., R.P., L.R., R.R., A.R., V.S., A.H.S., E.M.S., C.S., S.T., P.W., and M.C.Z. contributed to discussion of the content and reviewed and/or edited this paper before submission. All of the authors agreed with the last version of this paper.

\section{References}

1 Albright F, Burnett CH, Smith PH, Parson W. Pseudohypoparathyroidism - an example of "Seabright-Bantam syndrome". Endocrinology. 1942;30:922-32.

2 Mantovani G, Spada A, Elli FM. Pseudohypoparathyroidism and Gsa-cAMP-linked disorders: current view and open issues. Nat Rev Endocrinol. 2016 Jun;12(6):347-56.

3 Hanna P, Grybek V, Perez de Nanclares G, Tran LC, de Sanctis L, Elli F, et al. Genetic and Epigenetic Defects at the GNAS Locus Lead to Distinct Patterns of Skeletal Growth but Similar Early-Onset Obesity. J Bone Miner Res. 2018 Aug;33(8):1480-8.

4 Grüters-Kieslich A, Reyes M, Sharma A, Demirci C, DeClue TJ, Lankes E, et al. EarlyOnset Obesity: Unrecognized First Evidence for GNAS Mutations and Methylation Changes. J Clin Endocrinol Metab. 2017 Aug; 102(8):2670-7.

5 Shoemaker AH, Jüppner H. Nonclassic features of pseudohypoparathyroidism type 1A. Curr Opin Endocrinol Diabetes Obes. 2017 Feb;24(1):33-8.

6 Miyakawa Y, Takasawa K, Matsubara Y, Ihara K, Ohtsu Y, Kamasaki H, et al. Language delay and developmental catch-up would be a clinical feature of pseudohypoparathyroidism type 1A during childhood. Endocr J. 2019 Mar;66(3):215-21.

7 Perez KM, Lee EB, Kahanda S, Duis J, Reyes $\mathrm{M}$, Jüppner $\mathrm{H}$, et al. Cognitive and behavioral phenotype of children with pseudohypoparathyroidism type 1A. Am J Med Genet A. 2018 Feb;176(2):283-9.

8 Weinstein LS, Gejman PV, Friedman E, Kadowaki T, Collins RM, Gershon ES, et al. Mutations of the Gs alpha-subunit gene in Albright hereditary osteodystrophy detected by denaturing gradient gel electrophoresis. Proc Natl Acad Sci USA. 1990 Nov;87(21):828790.

9 Patten JL, Johns DR, Valle D, Eil C, Gruppuso PA, Steele G, et al. Mutation in the gene encoding the stimulatory $\mathrm{G}$ protein of adenylate cyclase in Albright's hereditary osteodystrophy. N Engl J Med. 1990 May;322(20):14129.

10 Davies SJ, Hughes HE. Imprinting in $\mathrm{Al}$ bright's hereditary osteodystrophy. J Med Genet. 1993 Feb;30(2):101-3.

11 Shore EM, Ahn J, Jan de Beur S, Li M, Xu M, Gardner RJ, et al. Paternally inherited inactivating mutations of the GNAS1 gene in progressive osseous heteroplasia. N Engl J Med. 2002 Jan;346(2):99-106.
12 Bastepe M, Fröhlich LF, Hendy GN, Indridason OS, Josse RG, Koshiyama H, et al. Autosomal dominant pseudohypoparathyroidism type $\mathrm{Ib}$ is associated with a heterozygous microdeletion that likely disrupts a putative imprinting control element of GNAS. J Clin Invest. 2003 Oct;112(8):1255-63.

13 Michot C, Le Goff C, Goldenberg A, Abhyankar A, Klein C, Kinning E, et al. Exome sequencing identifies PDE4D mutations as another cause of acrodysostosis. Am J Hum Genet. 2012 Apr;90(4):740-5.

14 Linglart A, Menguy C, Couvineau A, Auzan C, Gunes Y, Cancel M, et al. Recurrent PRKAR1A mutation in acrodysostosis with hormone resistance. N Engl J Med. 2011 Jun; 364(23):2218-26.

15 Thiele S, Mantovani G, Barlier A, Boldrin V, Bordogna P, De Sanctis L, et al. From pseudohypoparathyroidism to inactivating $\mathrm{PTH} /$ PTHrP signalling disorder (iPPSD), a novel classification proposed by the EuroPHP network. Eur J Endocrinol. 2016 Dec;175(6):1P17.

16 Mantovani G. Clinical review: Pseudohypoparathyroidism: diagnosis and treatment. J Clin Endocrinol Metab. 2011 Oct;96(10): 3020-30. 
17 Turan S, Bastepe M. GNAS Spectrum of Disorders. Curr Osteoporos Rep. 2015 Jun;13(3): 146-58.

18 Lee H, Graham JM Jr, Rimoin DL, Lachman RS, Krejci P, Tompson SW, et al. Exome sequencing identifies PDE4D mutations in acrodysostosis. Am J Hum Genet. 2012 Apr; 90(4):746-51.

19 Boda H, Uchida H, Takaiso N, Ouchi Y, Fujita N, Kuno A, et al. A PDE3A mutation in familial hypertension and brachydactyly syndrome. J Hum Genet. 2016 Aug;61(8):701-3.

20 Elli FM, deSanctis L, Ceoloni B, Barbieri AM, Bordogna P, Beck-Peccoz P, et al. Pseudohypoparathyroidism type Ia and pseudo-pseudohypoparathyroidism: the growing spectrum of GNAS inactivating mutations. Hum Mutat. 2013 Mar;34(3):411-6.

21 Elli FM, Linglart A, Garin I, de Sanctis L, Bordogna P, Grybek V, et al. The Prevalence of GNAS Deficiency-Related Diseases in a Large Cohort of Patients Characterized by the EuroPHP Network. J Clin Endocrinol Metab. 2016 Oct;101(10):3657-68.

22 Mantovani G, Bastepe M, Monk D, de Sanctis L, Thiele S, Usardi A, et al. Diagnosis and management of pseudohypoparathyroidism and related disorders: first international Consensus Statement. Nat Rev Endocrinol. 2018 Aug;14(8):476-500.

23 Thiele S, Werner R, Grötzinger J, Brix B, Staedt $\mathrm{P}$, Struve $\mathrm{D}$, et al. A positive genotypephenotype correlation in a large cohort of patients with Pseudohypoparathyroidism Type Ia and Pseudo-pseudohypoparathyroidism and 33 newly identified mutations in the GNAS gene. Mol Genet Genomic Med. 2015 Mar;3(2):111-20.

24 Shoback DM, Bilezikian JP, Costa AG, Dempster D, Dralle H, Khan AA, et al. Presentation of Hypoparathyroidism: Etiologies and Clinical Features. J Clin Endocrinol Metab. 2016 Jun;101(6):2300-12.

25 Gelfand IM, Eugster EA, DiMeglio LA. Presentation and clinical progression of pseudohypoparathyroidism with multi-hormone resistance and Albright hereditary osteodystrophy: a case series. J Pediatr. 2006 Dec;149(6): 877-80.

26 Linglart A, Fryssira H, Hiort O, Holterhus PM, Perez de Nanclares G, Argente J, et al. PRKAR1A and PDE4D mutations cause acrodysostosis but two distinct syndromes with or without GPCR-signaling hormone resistance. J Clin Endocrinol Metab. 2012 Dec; 97(12):E2328-38.

27 Elli FM, Bordogna P, de Sanctis L, Giachero F, Verrua E, Segni M, et al. Screening of PRKAR1A and PDE4D in a Large Italian Series of Patients Clinically Diagnosed With Albright Hereditary Osteodystrophy and/or Pseudohypoparathyroidism. J Bone Miner Res. 2016 Jun;31(6):1215-24.
28 Lindstrand A, Grigelioniene G, Nilsson D, Pettersson M, Hofmeister W, Anderlid BM, et al. Different mutations in PDE4D associated with developmental disorders with mirror phenotypes. J Med Genet. 2014 Jan;51(1):4554.

29 Linglart A, Maupetit-Méhouas S, Silve C. GNAS -Related Loss-of-Function Disorders and the Role of Imprinting. Horm Res Paediatr. 2013;79(3):119-29.

30 Bollerslev J, Rejnmark L, Marcocci C, Shoback DM, Sitges-Serra A, van Biesen W, et al.; European Society of Endocrinology. European Society of Endocrinology Clinical Guideline: treatment of chronic hypoparathyroidism in adults. Eur J Endocrinol. 2015 Aug; 173(2):G1-20.

31 Murray TM, Rao LG, Wong MM, Waddell JP, McBroom R, Tam CS, et al. Pseudohypoparathyroidism with osteitis fibrosa cystica: direct demonstration of skeletal responsiveness to parathyroid hormone in cells cultured from bone. J Bone Miner Res. 1993 Jan;8(1):83-91.

32 Kidd GS, Schaaf M, Adler RA, Lassman MN, Wray HL. Skeletal responsiveness in pseudohypoparathyroidism. A spectrum of clinical disease. Am J Med. 1980 May;68(5):772-81.

33 Sbrocchi AM, Rauch F, Lawson ML, Hadjiyannakis S, Lawrence S, Bastepe M, et al. Osteosclerosis in two brothers with autosomal dominant pseudohypoparathyroidism type 1b: bone histomorphometric analysis. Eur J Endocrinol. 2011 Feb;164(2):295-301.

34 Neary NM, El-Maouche D, Hopkins R, Libutti SK, Moses AM, Weinstein LS. Development and treatment of tertiary hyperparathyroidism in patients with pseudohypoparathyroidism type 1B. J Clin Endocrinol Metab. 2012 Sep;97(9):3025-30.

35 Hansen DW, Nebesio TD, DiMeglio LA, Eugster EA, Imel EA. Prevalence of Nephrocalcinosis in Pseudohypoparathyroidism: Is Screening Necessary? J Pediatr. 2018 Aug; 199:263-6.

36 Chen YJ, Shu SG, Chi CS. Pseudohypoparathyroidism: report of seven cases. Acta Paediatr Taiwan. 2005 Nov-Dec;46(6):374-80.

37 Bhadada SK, Bhansali A, Upreti V, Subbiah S, Khandelwal N. Spectrum of neurological manifestations of idiopathic hypoparathyroidism and pseudohypoparathyroidism. Neurol India. 2011 Jul-Aug;59(4):586-9.

38 Kadilli I, Colicchio S, Guglielmo R, Vollono C, Della Marca G, Janiri L. Clinical insights by the presence of bipolar disorder in pseudohypoparathyroidism type 1A. Gen Hosp Psychiatry. 2015 Sep-Oct;37(5):497.e3-5.

39 Lemos MC, Thakker RV. GNAS mutations in Pseudohypoparathyroidism type 1a and related disorders. Hum Mutat. 2015 Jan;36(1): 11-9.

40 Lynch DC, Dyment DA, Huang L, Nikkel SM, Lacombe D, Campeau PM, et al.; FORGE Canada Consortium. Identification of novel mutations confirms PDE4D as a major gene causing acrodysostosis. Hum Mutat. 2013 Jan;34(1):97-102.
41 Underbjerg L, Sikjaer T, Mosekilde L, Rejnmark L. Pseudohypoparathyroidism - epidemiology, mortality and risk of complications. Clin Endocrinol (Oxf). 2016 Jun;84(6):90411.

42 Grajewski RS, Koch KR, Koch HR, Ciotu IM, Cursiefen C, Heindl LM. Cataract in pseudohypoparathyroidism. J Cataract Refract Surg. 2016 Jul;42(7):1094-6.

43 Clarke BL, Brown EM, Collins MT, Jüppner H, Lakatos P, Levine MA, et al. Epidemiology and Diagnosis of Hypoparathyroidism. J Clin Endocrinol Metab. 2016 Jun;101(6):2284-99.

44 Sunder RA, Singh M. Pseudohypoparathyroidism: a series of three cases and an unusual presentation of ocular tetany. Anaesthesia. 2006 Apr;61(4):394-8.

45 Maheshwari R, Rani RP, Prasad RN, Reddy KT, Reddy AP. Visual disturbances as a presenting feature of pseudohypoparathyroidism. Indian J Endocrinol Metab. 2013 Oct; 17(7 Suppl 1):S219-20.

46 Reis MT, Matias DT, Faria ME, Martin RM. Failure of tooth eruption and brachydactyly in pseudohypoparathyroidism are not related to plasma parathyroid hormone-related protein levels. Bone. 2016 Apr;85:138-41.

47 Ritchie GM. Dental manifestations of pseudohypoparathyroidism. Arch Dis Child. 1965 Oct;40(213):565-72.

48 Hejlesen J, Underbjerg L, Gjørup H, BlochZupan A, Sikjaer T, Rejnmark L, et al. Dental Findings in Patients With Non-surgical Hypoparathyroidism and Pseudohypoparathyroidism: A Systematic Review. Front Physiol. 2018 Jun;9:701.

49 Le Norcy E, Reggio-Paquet C, de Kerdanet M, Mignot B, Rothenbuhler A, Chaussain C, et al Dental and craniofacial features associated with GNAS loss of function mutations. Eur J Orthod. 2019 Nov:cjz084.

50 Schlund M, Depeyre A, Kohler F, Nicot R, Ferri J. Cranio-Maxillofacial and Dental Findings in Albright's Hereditary Osteodystrophy and Pseudohypoparathyroidism. Cleft Palate Craniofac J. 2019 Jul;56(6):831-6.

51 Salemi P, Skalamera Olson JM, Dickson LE, Germain-Lee EL. Ossifications in Albright Hereditary Osteodystrophy: Role of Genotype, Inheritance, Sex, Age, Hormonal Status, and BMI. J Clin Endocrinol Metab. 2018 Jan; 103(1):158-68.

52 Adegbite NS, Xu M, Kaplan FS, Shore EM, Pignolo RJ. Diagnostic and mutational spectrum of progressive osseous heteroplasia $(\mathrm{POH})$ and other forms of GNAS-based heterotopic ossification. Am J Med Genet A. 2008 Jul;146A(14):1788-96.

53 Pignolo RJ, Xu M, Russell E, Richardson A, Kaplan J, Billings PC, et al. Heterozygous inactivation of Gnas in adipose-derived mesenchymal progenitor cells enhances osteoblast differentiation and promotes heterotopic ossification. J Bone Miner Res. 2011 Nov;26(11): 2647-55. 
54 Regard JB, Malhotra D, Gvozdenovic-Jeremic J, Josey M, Chen M, Weinstein LS, et al. Activation of Hedgehog signaling by loss of GNAS causes heterotopic ossification. Nat Med. 2013 Nov; 19(11):1505-12.

55 Huso DL, Edie S, Levine MA, Schwindinger $\mathrm{W}$, Wang $\mathrm{Y}$, Jüppner $\mathrm{H}$, et al. Heterotopic ossifications in a mouse model of Albright hereditary osteodystrophy. PLoS One. 2011; 6(6):e21755.

56 Convente MR, Wang H, Pignolo RJ, Kaplan FS, Shore EM. The immunological contribution to heterotopic ossification disorders. Curr Osteoporos Rep. 2015 Apr;13(2):11624.

57 Pignolo RJ, Ramaswamy G, Fong JT, Shore EM, Kaplan FS. Progressive osseous heteroplasia: diagnosis, treatment, and prognosis. Appl Clin Genet. 2015 Jan;8:37-48.

58 Schrander DE, Welting TJ, Caron MM, Schrander JJ, van Rhijn LW, Körver-Keularts I, et al. Endochondral ossification in a case of progressive osseous heteroplasia in a young female child. J Pediatr Orthop B. 2014 Sep; 23(5):477-84.

59 de Sanctis L, Vai S, Andreo MR, Romagnolo D, Silvestro L, de Sanctis C. Brachydactyly in 14 genetically characterized pseudohypoparathyroidism type Ia patients. J Clin Endocrinol Metab. 2004 Apr;89(4):1650-5.

60 Virágh K, Töke J, Sallai A, Jakab Z, Rácz K, Tóth M. Gradual development of brachydactyly in pseudohypoparathyroidism. J Clin Endocrinol Metab. 2014 Jun;99(6):1945-6.

61 Joseph AW, Shoemaker AH, Germain-Lee EL. Increased prevalence of carpal tunnel syndrome in Albright hereditary osteodystrophy. J Clin Endocrinol Metab. 2011 Jul;96(7): 2065-73.

62 Sanchez J, Perera E, Jan de Beur S, Ding C, Dang A, Berkovitz GD, et al. Madelung-like deformity in pseudohypoparathyroidism type 1b. J Clin Endocrinol Metab. 2011 Sep; 96(9):E1507-11.

63 Okada K, Iida K, Sakusabe N, Saitoh H, Abe E, Sato K. Pseudohypoparathyroidism-associated spinal stenosis. Spine. 1994 May;19(10 Supplement):1186-9.

64 García García E, Rivero Garvía M, Alonso Luengo O. Craniosynostosis as the first manifestation of an Albright's osteodystrophy associated with pseudohypoparathyroidism type 1A. Med Clin (Barc). 2017;149(4):184-5.

65 Mantovani G, Ferrante E, Giavoli C, Linglart A, Cappa M, Cisternino M, et al. Recombinant human GH replacement therapy in children with pseudohypoparathyroidism type Ia: first study on the effect on growth. J Clin Endocrinol Metab. 2010 Nov;95(11):5011-7.

66 Kinoshita K, Minagawa M, Anzai M, Sato Y, Kazukawa I, Shimohashi K, et al. Characteristic Height Growth Pattern in Patients with Pseudohypoparathyroidism: comparison between Type 1a and Type 1b. Clin Pediatr Endocrinol. 2007;16(1):31-6.
67 Long DN, McGuire S, Levine MA, Weinstein LS, Germain-Lee EL. Body mass index differences in pseudohypoparathyroidism type 1a versus pseudopseudohypoparathyroidism may implicate paternal imprinting of Galpha(s) in the development of human obesity. J Clin Endocrinol Metab. 2007 Mar; 92(3):1073-9.

68 Wang L, Shoemaker AH. Eating behaviors in obese children with pseudohypoparathyroidism type 1a: a cross-sectional study. Int J Pediatr Endocrinol. 2014;2014(1):21.

69 Perez KM, Curley KL, Slaughter JC, Shoemaker AH. Glucose homeostasis and energy balance in children with pseudohypoparathyroidism. J Clin Endocrinol Metab. 2018 Nov; 103(11):4265-74.

70 Roizen JD, Danzig J, Groleau V, McCormack S, Casella A, Harrington J, et al. Resting Energy Expenditure Is Decreased in Pseudohypoparathyroidism Type 1A. J Clin Endocrinol Metab. 2016 Mar;101(3):880-8.

71 Shoemaker AH, Lomenick JP, Saville BR, Wang W, Buchowski MS, Cone RD. Energy expenditure in obese children with pseudohypoparathyroidism type 1a. Int J Obes. 2013 Aug;37(8):1147-53.

72 Carel JC, Le Stunff C, Condamine L, Mallet E, Chaussain JL, Adnot P, et al. Resistance to the lipolytic action of epinephrine: a new feature of protein Gs deficiency. J Clin Endocrinol Metab. 1999 Nov;84(11):4127-31.

73 Mantovani G, Maghnie M, Weber G, De Menis E, Brunelli V, Cappa M, et al. Growth hormone-releasing hormone resistance in pseudohypoparathyroidism type ia: new evidence for imprinting of the Gs alpha gene. J Clin Endocrinol Metab. 2003 Sep;88(9): 4070-4.

74 Germain-Lee EL, Groman J, Crane JL, Jan de Beur SM, Levine MA. Growth hormone deficiency in pseudohypoparathyroidism type 1a: another manifestation of multihormone resistance. J Clin Endocrinol Metab. 2003 Sep; 88(9):4059-69.

75 Liu JJ, Russell E, Zhang D, Kaplan FS, Pignolo RJ, Shore EM. Paternally inherited gsa mutation impairs adipogenesis and potentiates a lean phenotype in vivo. Stem Cells. 2012 Jul; 30(7):1477-85.

76 Germain-Lee EL. Management of pseudohypoparathyroidism. Curr Opin Pediatr. 2019 Aug;31(4):537-49.

77 Landreth H, Malow BA, Shoemaker AH. Increased Prevalence of Sleep Apnea in Children with Pseudohypoparathyroidism Type 1a. Horm Res Paediatr. 2015;84(1):1-5.

78 Curley KL, Kahanda S, Perez KM, Malow BA, Shoemaker AH. Obstructive Sleep Apnea and Otolaryngologic Manifestations in Children with Pseudohypoparathyroidism. Horm Res Paediatr. 2018;89(3):178-83

79 Muniyappa R, Warren MA, Zhao X, Aney SC, Courville $\mathrm{AB}$, Chen $\mathrm{KY}$, et al. Reduced insulin sensitivity in adults with pseudohypoparathyroidism type 1a. J Clin Endocrinol Metab. 2013 Nov;98(11):E1796-801.
80 Underbjerg L, Sikjaer T, Rejnmark L. Cardiovascular findings in patients with nonsurgical hypoparathyroidism and pseudohypoparathyroidism: A cohort study. Clin Endocrinol (Oxf). 2019 Apr;90(4):592-600.

81 Brickman AS, Stern N, Sowers JR. Hypertension in pseudohypoparathyroidism type I. Am J Med. 1988 Dec;85(6):785-92.

82 Mouallem M, Shaharabany M, Weintrob N, Shalitin S, Nagelberg N, Shapira H, et al. Cognitive impairment is prevalent in pseudohypoparathyroidism type Ia, but not in pseudopseudohypoparathyroidism: possible cerebral imprinting of Gsalpha. Clin Endocrinol (Oxf). 2008 Feb;68(2):233-9.

83 Farfel Z, Friedman E. Mental deficiency in pseudohypoparathyroidism type I is associated with Ns-protein deficiency. Ann Intern Med. 1986 Aug;105(2):197-9.

84 Chen M, Wang J, Dickerson KE, Kelleher J, Xie T, Gupta D, et al. Central nervous system imprinting of the G protein G(s)alpha and its role in metabolic regulation. Cell Metab. 2009 Jun;9(6):548-55.

85 Martínez-Lage JF, Guillén-Navarro E, LópezGuerrero AL, Almagro MJ, Cuartero-Pérez B, de la Rosa P. Chiari type 1 anomaly in pseudohypoparathyroidism type Ia: pathogenetic hypothesis. Childs Nerv Syst. 2011 Dec; 27(12):2035-9.

86 Kashani P, Roy M, Gillis L, Ajani O, Samaan MC. The Association of Pseudohypoparathyroidism Type Ia with Chiari Malformation Type I: A Coincidence or a Common Link? Case Rep Med. 2016;2016:7645938.

87 Visconti P, Posar A, Scaduto MC, Russo A, Tamburrino F, Mazzanti L. Neuropsychiatric phenotype in a child with pseudohypoparathyroidism. J Pediatr Neurosci. 2016 Jul-Sep; 11(3):267-70.

88 Germain-Lee EL, Ding CL, Deng Z, Crane JL, Saji M, Ringel MD, et al. Paternal imprinting of Galpha(s) in the human thyroid as the basis of TSH resistance in pseudohypoparathyroidism type 1a. Biochem Biophys Res Commun. 2002 Aug;296(1):67-72.

89 Mantovani G, Ballare E, Giammona E, BeckPeccoz P, Spada A. The gsalpha gene: predominant maternal origin of transcription in human thyroid gland and gonads. J Clin Endocrinol Metab. 2002 Oct;87(10):4736-40.

90 Liu J, Erlichman B, Weinstein LS. The stimulatory $\mathrm{G}$ protein alpha-subunit $\mathrm{Gs}$ alpha is imprinted in human thyroid glands: implications for thyroid function in pseudohypoparathyroidism types $1 \mathrm{~A}$ and $1 \mathrm{~B}$. J Clin Endocrinol Metab. 2003 Sep;88(9):4336-41.

91 Lazarus J, Brown RS, Daumerie C, Hubalewska-Dydejczyk A, Negro R, Vaidya B. 2014 European thyroid association guidelines for the management of subclinical hypothyroidism in pregnancy and in children. Eur Thyroid J. 2014 Jun;3(2):76-94.
Updated Practical Tool: Diagnosis and Treatment of PHP-Related Disorders
Horm Res Paediatr 2020:93:182-196 
92 Namnoum AB, Merriam GR, Moses AM, Levine MA. Reproductive dysfunction in women with Albright's hereditary osteodystrophy. J Clin Endocrinol Metab. 1998 Mar; 83(3):824-9.

93 Linglart A, Carel JC, Garabédian M, Lé T, Mallet E, Kottler ML. GNAS1 lesions in pseudohypoparathyroidism Ia and Ic: genotype phenotype relationship and evidence of the maternal transmission of the hormonal resistance. J Clin Endocrinol Metab. 2002 Jan;87(1):189-97.

94 Mantovani G, Bondioni S, Linglart A, Maghnie M, Cisternino M, Corbetta S, et al. Genetic analysis and evaluation of resistance to thyrotropin and growth hormonereleasing hormone in pseudohypoparathyroidism type Ib. J Clin Endocrinol Metab. 2007 Sep;92(9):3738-42.

95 Takatani R, Molinaro A, Grigelioniene G, Tafaj O, Watanabe T, Reyes M, et al. Analysis of Multiple Families With Single Individuals Affected by Pseudohypoparathyroidism Type Ib (PHP1B) Reveals Only One Novel Maternally Inherited GNAS Deletion. J Bone Miner Res. 2016 Apr;31(4): 796-805.

96 Long DN, Levine MA, Germain-Lee EL. Bone mineral density in pseudohypoparathyroidism type 1a. J Clin Endocrinol Metab. 2010 Sep;95(9):4465-75.
Underbjerg L, Malmstroem S, Sikjaer T, Rejnmark L. Bone Status Among Patients With Nonsurgical Hypoparathyroidism, Autosomal Dominant Hypocalcaemia, and Pseudohypoparathyroidism: A Cohort Study. J Bone Miner Res. 2018 Mar;33(3): 467-77.

98 Wägar G, Lehtivuori J, Salvén I, Backman R, Sivula A. Pseudohypoparathyroidism associated with hypercalcitoninaemia. Acta Endocrinol (Copenh). 1980 Jan;93(1):43-8.

99 Vlaeminck-Guillem V, D’herbomez M, Pigny P, Fayard A, Bauters C, Decoulx M, et al. Pseudohypoparathyroidism Ia and hypercalcitoninemia. J Clin Endocrinol Metab. 2001 Jul;86(7):3091-6.

100 Levine MA, Downs RW Jr, Moses AM, Breslau NA, Marx SJ, Lasker RD, et al. Resistance to multiple hormones in patients with pseudohypoparathyroidism. Association with deficient activity of guanine nucleotide regulatory protein. Am J Med. 1983 Apr; 74(4):545-56.

101 Garin I, Elli FM, Linglart A, Silve C, de Sanctis L, Bordogna P, et al. Novel microdeletions affecting the GNAS locus in pseudohypoparathyroidism: characterization of the underlying mechanisms. J Clin Endocrinol Metab. 2015 Apr;100(4):E681-7.

102 Turan S, Thiele S, Tafaj O, Brix B, Atay Z, Abali $S$, et al. Evidence of hormone resistance in a pseudo-pseudohypoparathyroidism patient with a novel paternal mutation in GNAS. Bone. 2015 Feb;71:53-7.
103 Liu J, Litman D, Rosenberg MJ, Yu S, Biesecker LG, Weinstein LS. A GNAS1 imprinting defect in pseudohypoparathyroidism type IB. J Clin Invest. 2000 Nov;106(9): 1167-74.

104 Liu J, Nealon JG, Weinstein LS. Distinct patterns of abnormal GNAS imprinting in familial and sporadic pseudohypoparathyroidism type IB. Hum Mol Genet. 2005 Jan; 14(1):95-102.

105 Takatani R, Minagawa M, Molinaro A, Reyes M, Kinoshita K, Takatani T, et al. Similar frequency of paternal uniparental disomy involving chromosome $20 \mathrm{q}$ (patUPD20q) in Japanese and Caucasian patients affected by sporadic pseudohypoparathyroidism type Ib (sporPHP1B). Bone. 2015 Oct;79:15-20.

106 Bastepe M, Lane AH, Jüppner H. Paternal uniparental isodisomy of chromosome $20 \mathrm{q}$-and the resulting changes in GNAS1 methylation-as a plausible cause of pseudohypoparathyroidism. Am J Hum Genet. 2001 May;68(5):1283-9.

107 Alsum Z, Abu Safieh L, Nygren AO, AlHamed MA, Alkuraya FS. Methylation-specific multiplex-ligation-dependent probe amplification as a rapid molecular diagnostic tool for pseudohypoparathyroidism type 1b. Genet Test Mol Biomarkers. 2010 Feb; 14(1):135-9. 